\title{
Reações das políticas educacionais estaduais nas escolas: um estudo de caso em escolas do Ceará, Goiás, Pernambuco e São Paulo
}

* (Universidade Estadual do Ceará [Uece], Fortaleza, CE)

** (Universidade Estadual do Ceará [Uece], Fortaleza, CE)

$\star \star \star$ (Cenpec, São Paulo, SP)

$\star \star \star \star$ (Cenpec, São Paulo, SP)

\author{
Sofia Lerche Vieira* \\ Eloísa Maia Vidal ** \\ Pâmela Félix Freitas *** \\ Antônio Augusto Gomes Batista****
}

Resumo: Este artigo se propõe a analisar como escolas de ensino médio de quatro estados - Ceará, Goiás, Pernambuco e São Paulo - reagem às políticas concebidas pelos órgãos centrais estaduais. As reações - captadas a partir dos depoimentos de diretores, coordenadores pedagógicos, professores e alunos - são apresentadas segundo cinco dimensões do modelo comum que organiza as políticas dos quatro estados: diversificação da oferta; currículo; avaliação de resultados de desempenho escolar; monitoramento do processo ensino-aprendizado e formação/recrutamento de docentes. A análise revelou que os efeitos produzidos pelas políticas nas escolas nem sempre são os esperados. A diversificação das condições da oferta de ensino médio intensificou condições desiguais de atendimento, evidenciando a necessidade de políticas orientadas para a promoção da equidade.

Palavras-chave: Ensino médio. Política educacional. Implementação. Reações das escolas. 
Este artigo integra a pesquisa intitulada "Políticas para o ensino médio: 0 caso de quatro estados", desenvolvida pelo Centro de Estudos e Pesquisas em Educação e Ação Comunitária (Cenpec), apoiada pela Fundação Tide Setubal entre 2015 e 2016. Ele se propõe a compreender como escolas de ensino médio (doravante EM) de quatro estados brasileiros - Ceará, Pernambuco, São Paulo e Goiás - respondem às políticas concebidas por órgãos centrais estaduais, tendo como fio condutor as dimensões apreendidas por meio da análise - apresentada no artigo "Políticas para o ensino médio: o caso de quatro estados (Ceará e de Goiás, Pernambuco e São Paulo)" - do modelo que organiza as políticas para o EM dos estados selecionados ${ }^{1}$ : diversificação da oferta, currículo, avaliação de resultados de desempenho escolar, monitoramento do processo de ensino-aprendizado e formação/recrutamento de docentes. As reações das escolas às políticas educacionais de ensino médio foram observadas com base na análise de depoimentos de diretores, coordenadores pedagógicos, professores e alunos.

Para a coleta desses dados, procedeu-se da seguinte maneira e de acordo com o pressuposto que se apresenta em seguida. Em geral, as políticas públicas educacionais tendem a assumir uma natureza universalista, que desconsidera as especificidades das escolas localizadas em contextos marcados pela desigualdade socioespacial. Nos grandes centros urbanos ela se expressa, na maior parte das vezes, pela oposição entre centro e periferia. Já na comparação entre centros urbanos, a desigualdade se manifesta pelas diferentes condições que os municípios possuem para agregar renda, serviços, capital humano e instituições, como as educacionais e culturais (o porte dos municípios, por exemplo, é um indicador, ainda que grosseiro, dessa desigualdade). As desigualdades socioespaciais tendem a se expressar ainda na dinâmica da relação urbano versus rural² .

Por essa razão, em cada estado foram investigadas seis escolas, em três tipos de municípios: pequeno porte, com alto índice de ruralidade ${ }^{3}$; médio porte; e grande porte, em escolas localizadas na periferia das regiões metropolitanas. No caso dessas escolas - vale dizer, daquelas situadas em regiões de alta

Os critérios de seleção dos estados são apresentados no artigo "Políticas para o ensino médio: o caso de quatro estados”, de Batista et. al (2016), publicado neste número da Cadernos Cenpec.

2 Como vêm mostrando outras pesquisas realizadas pelo Cenpec, o território socialmente vulnerável demanda políticas específicas ou focalizadas para fazer face a seus problemas peculiares, inclusive aos desafios gerados por políticas universalistas (ver: ÉRNICA; BATISTA, 2012; ALVES et al., 2015; BATISTA; CARVALHO-SILVA, 2013; RIBEIRO, MELLO, BATISTA, 2015).

3 Definidos na proporção de $70 \%$ de habitantes em zona rural. 
vulnerabilidade social -, foram priorizadas ${ }^{4}$ aquelas com nível de proficiência em avaliações externas superior em relação a escolas em situação similar.

Como um elemento central das políticas dos quatro estados é a oferta de matrícula em tempo integral, concomitante à oferta em tempo parcial, das seis escolas, três eram do primeiro tipo e as demais do segundo.

A pesquisa nas escolas foi predominante qualitativa. A coleta de dados nas escolas ocorreu em duas etapas, no primeiro e no segundo semestre de 2015. Lançou mão de procedimentos como entrevistas individuais, grupos focais, observação do cotidiano escolar, diário de campo e questionários. Os principais informantes foram gestores de escolas, professores e estudantes. Se a primeira etapa de coleta teve objetivos mais gerais, a segunda pôde ser mais focalizada, conduzida por um conjunto de hipóteses e direções estabelecidas pela análise de dados obtidos na primeira fase. Como se indicou no artigo "Políticas para o ensino médio: o caso de quatro estados", a coleta de dados e sua primeira análise foram realizadas pelas equipes locais de pesquisa, cabendo à equipe do Cenpec a integração dos resultados.

\section{PRESSUPOSTOS}

O desenho metodológico adotado considera um aspecto importante da implementação de uma política educacional o envolvimento de dois grupos de atores - os gestores escolares (diretores e coordenadores pedagógicos), que coordenam as ações; e os docentes, os efetivos implementadores. Evidentemente, os estudantes são importantes atores desse processo. Por essa razão, suas percepções também foram cotejadas. Esses atores reagem de diferentes formas às políticas prescritas e, na prática, conforme Fullan (2009), as decisões de instâncias centrais não são automaticamente cumpridas, pois, dada a dinâmica de sua aplicação nos processos de execução, o desenho das políticas pode estar sujeito a ajustes e adaptações, podendo adquirir novos contornos, dependendo do contexto de sua aplicação e da adesão dos agentes. Se a fase de concepção e elaboração de políticas resguarda disputas, conflitos, acordos e negociações de interesses entre os atores envolvidos, é na implementação que se colocam em prática os resultados desse conflito (PASSONE, 2012); por isso, encontra-se, nessa fase do ciclo de uma política, um campo fértil de possibilidades analíticas que permitem

4 As regiões potencialmente vulneráveis foram identificadas com base em indicadores como o Índice de Desenvolvimento Humano de Munícipios (IDH-M) e o Índice de Desenvolvimento Humano de Bairros (IDH-B). Adotou-se também o Indicador de Nível Socioeconômico das escolas (do Inep) como medida auxiliar. 
explorar as condições para a efetivação prática de uma política.

A busca de elementos para interpretar o movimento entre a formulação e a implementação das políticas educacionais encontrou no modelo de “governança educacional multiescalar”, de Roger Dale (2010), um referencial fecundo para a análise pretendida.

A forma como as políticas chegam às escolas está estreitamente relacionada a duas condicionalidades intrínsecas à sua formulação e implementação. De um lado, as escolas se configuram como espaços de reinvenção das políticas (BALL, MAGUIRE e BRAUN, 2012) e, por isso mesmo, "encenam" políticas, desencadeiam formas próprias e peculiares de lidar com elas. De outro, há que se destacar que cada unidade escolar possui uma cultura organizacional própria (TORRES, 2005). Nessa perspectiva, as iniciativas governamentais são consideradas como "fatores exógenos" às escolas (porque originários do Ministério da Educação ou das secretarias estaduais de Educação), ao passo que seus próprios recursos (humanos - professores, equipe gestora, alunos e funcionários -, materiais e imateriais) são "fatores endógenos". Como cada escola é fruto de uma história construída a partir dos caminhos que a levaram a constituir sua identidade atual, não são homogêneas as formas como interpretam e reinterpretam as políticas. Esta foi, sem dúvida, uma das primeiras constatações da pesquisa. Nas escolas investigadas, é forte a percepção da escola como uma unidade isolada, bem como das políticas das secretarias de educação para a rede como ações externas que podem, na maior parte das vezes, prejudicar o bom funcionamento da escola. Os atores não se percebem como parte de um sistema de ensino, mas como parte das escolas em que atuam. Sua identidade é, primeiramente, construída na relação com o estabelecimento de ensino e as políticas dos órgãos centrais não são percebidas como tais - vale dizer, como políticas ou um conjunto de medidas que visam alcançar um determinado fim -, mas como modificações que perturbam a cultura da escola. Por isso, é tensa - e em geral negada - a identidade com a rede de ensino: "eles mandam essas mudanças"; "o novo currículo que eles fizeram"; "essa escola integral que eles criaram"; "fizeram essas modificações e agora a gente tem de se virar" - todas essas sentenças são expressões dessa ausência de sentido de pertencimento a uma rede, bem como de afirmação de uma identidade própria, ligada à unidade escolar.

Segundo a perspectiva de Dale (2010), o desenho e a implementação das

Nele foram feitas algumas adequações tendo em vista as peculiaridades da realidade brasileira e as incumbências da União, dos estados e das escolas (LDB, Art. 8ํㅜ 9ํㅜ, 10 e 12) na oferta de EM. 
políticas educacionais contemporâneas do mundo globalizado são fruto de uma articulação entre escalas de governança (supranacional, nacional e subnacional), instituições de coordenação (Estado, mercado, comunidade e família) e atividades de governança (financiamento, propriedade, fornecimento e regulação) ${ }^{6}$. Nesses termos, pode-se dizer que as políticas educacionais de ensino médio resultam de uma combinação desses três elementos de governança, cuja concretização varia em função de diferentes contextos, bem como das instituições e atores que aí se fazem presentes e operacionalizam as políticas (BALL; MAGUIRE; BRAUN, 2012; TORRES, 2005).

Como observa Maroy (2011, p. 37), “situações de partida diferentes conduzem a políticas diferentes". Assim, ainda que as políticas possam ser as mesmas, seus resultados não o são. Quando uma iniciativa supranacional aporta no contexto nacional e/ou subnacional, uma nova síntese ocorre, produzindo aquilo que tem se denominado "efeito de hibridação" (BARROSO, 2005; MAROY, 2011). O conhecimento de tal movimento contribui para compreender como orientações nacionais advindas de leis e políticas comuns podem ser apropriadas de forma diferenciada pelos estados e pelas escolas integrantes de suas redes. Nesse sentido, uma vez formuladas, as políticas são recontextualizadas nos diferentes espaços aonde chegam e são implementadas, num movimento que Ball, Maguire e Braun (2012) descreve como capacidade de encenação dos atores locais. A Figura 1 expressa a multiescalaridade da política educacional brasileira, à qual se acrescenta o nível local7.

Figura 1 - "Escalas de governança” da política educacional
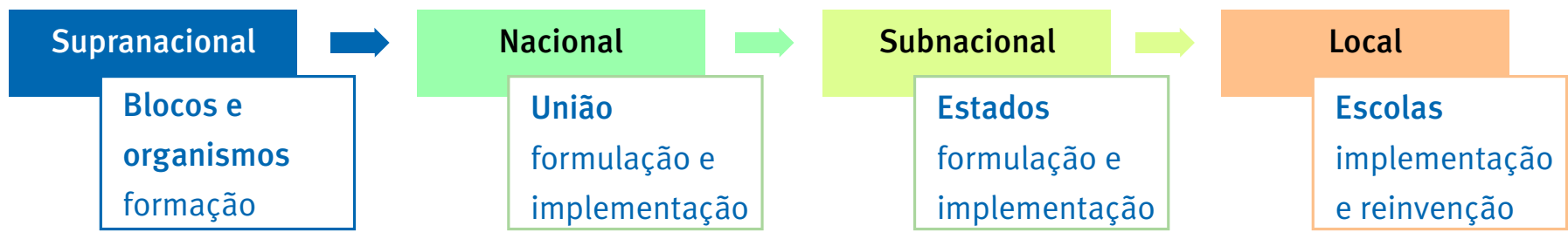

Fonte: Elaborada pelos autores.

Em virtude dos objetivos da pesquisa, as atividades de governança (financiamento, propriedade, fornecimento e regulação) não serão aqui aprofundadas.

É oportuno observar que este artigo faz uma adaptação livre do modelo de Dale ao caso brasileiro, acrescentando ao mesmo o nível "local”, ao mesmo tempo que se procura traduzir as esferas onde as diferentes escalas se materializam: no âmbito internacional, os blocos; no nacional, as diferentes esferas do Poder Público: a União, estados e municípios. 
Como se veem, as políticas possuem distintas escalas e para melhor compreendê-las é preciso examiná-las em seus diversos níveis. Este estudo dedica-se a se aproximar da escola, considerando ser este o terreno de concretização das políticas públicas educacionais. Tendo por interesse melhor compreender as políticas no âmbito subnacional (os estados) e local (escolas), este artigo dedica-se a explorar as reações das escolas às políticas pela voz dos gestores, professores e alunos.

Os dados da pesquisa de campo serão apresentados e discutidos a seguir, à luz das cinco dimensões já apontadas.

\section{DIVERSIFICAÇÃO DA OFERTA DO ENSINO MÉDIO E MECANISMOS DE SELETIVIDADE}

Embora a diversificação de condições da oferta de ensino médio já estivesse há tempos presente nos turnos diurnos e noturno, assim como na Educação de Jovens e Adultos (EJA), e aparecesse de forma contundente nas escolas ou extensões rurais ${ }^{8}$, esse fenômeno adquire maior visibilidade quando, por indução de políticas federais, emergem os modelos de ensino médio de tempo integral, propedêutico ou integrado à educação profissional.

O que antes se colocava como demanda decorrente das condições socioeconômicas ou até mesmo de territorialidade por parte dos alunos (o ensino noturno atendia os alunos que trabalhavam e, nas escolas rurais, atendiam aqueles que não podiam se deslocar para a cidade), agora se expressa como uma iniciativa do Estado que, claramente, explicita condições de atendimento desiguais, como se viu por meio da análise apresentada no artigo de Batista et al. (2016), neste número.

Se muitos gestores e professores reconheciam as agudas diferenças presentes na oferta de ensino médio diurno e noturno, urbano e rural, e consideravam que havia problemas de equidade no atendimento dos alunos, a proposta de ensino médio de tempo integral introduz novas variáveis, ambas oferecidas

\footnotetext{
Os anexos ou extensões rurais, identificados na oferta de ensino médio no Ceará, existem desde o começo dos anos 2000, de acordo com as informações obtidas junto aos depoentes. Via de regra, funcionam em escolas municipais cedidas pela prefeitura para, no turno noturno, atender a clientela de ensino médio. A matrícula de ensino médio é variável, existindo situações em que mais de 150 alunos frequentam esses espaços. É vinculado à escola estadual, localizada na sede, que além de assumir a matrícula no Censo Escolar, também dá todo o suporte pedagógico e de gestão. Segundo dados obtidos junto à Secretaria Estadual de Educação (Seduc), em 2015 existiam 402 anexos, em 173 unidades escolares, atendendo 34.787 alunos. Nos demais estados da pesquisa, esses dados não foram mapeados.
} 
especificamente nas localidades urbanas, em regime de sete ou mais horas diárias, que impõem critérios que levam à exclusão de parcela expressiva de jovens, aumentando a iniquidade entre escolas, alunos e até mesmo condições laborais dos professores e gestores.

No Ceará, por exemplo, ocorre uma seleção oficial, baseada na análise do histórico escolar do estudante, para o ingresso nas escolas de ensino médio de tempo integral (integrado à educação profissional); $80 \%$ das vagas são destinadas aos egressos da rede pública; $20 \%$ aos da rede particular:

\begin{abstract}
A gente sustentar durante quatro ou cinco anos, como nós sustentamos aqui, usar única e exclusivamente as regras estabelecidas em uma determinação, em uma orientação, em uma portaria de que o único critério para selecionar os alunos era por notas... Porque de vez em quando alguém chega querendo impor que você tem que mudar as regras para beneficiar um ou outro, alguma pessoa da comunidade ou algum político local e você dizer: "eu não posso mudar por que... Eu até queria ajudar seu filho, mas se eu ajudar ele, eu vou estar prejudicando alguém, que para ele entrar alguém tem que sair!” [...] (Ceará, diretor de escola de município de pequeno porte e alto índice de ruralidade).
\end{abstract}

[Os alunos serem selecionados apenas pela nota] é um critério muito falho, o que é que acontece? Nós recebemos alunos, este ano... Por exemplo, os alunos do curso de redes... O que entrou com menor nota tinha 8,5. Aí você imagina que é um aluno bom [...] (Ceará, diretor de escola da região metropolitana).

\title{
[...] Acredito que muito mais do que isso teria vontade de vir para cá. Mas como eles já sabem que existe um processo de seleção que é fundamentado exclusivamente nas notas do ensino fundamental, muitos já sabem que não têm nota suficiente para isso (Ceará, diretor de escola de município de pequeno porte e alto índice de ruralidade).
}

No caso de Pernambuco não há, oficialmente, seleção dos alunos nas escolas de ensino médio integral. Os estudantes informam à escola onde desejam cursar o ensino médio e esta envia a lista para a secretaria preencher as vagas. A distribuição é geograficamente orientada. Para alunos oriundos da rede privada, a inscrição é feita por ordem de chegada, mas primeiro entram todos os alunos da rede pública e, se houver vagas remanescentes, abre-se “inscrição de bancada” para os da rede privada.

Já em Goiás, a matrícula é feita pela internet. O aluno aponta três escolas e é alocado por ordem de prioridade, onde já estuda seu irmão, ou na escola mais próxima de sua residência. Os veteranos apenas renovam a matrícula, o que não impede que a escola, na prática, também "reserve" vagas e faça matrícula de balcão. 
Em São Paulo, o Programa de Ensino Integral (PEI) ${ }^{9}$, denominado, em 2017, Novo Modelo de Escola de Tempo Integral, é implantado em escolas preexistentes. Desse modo, segundo a Resolução número 49, de 2013, da Secretaria de Estado da Educação, as escolas devem, a partir da implementação do programa, dar prioridade aos alunos já matriculados na unidade escolar e, nas novas matrículas, seguir a legislação vigente para a matrícula do ensino médio regular, que interdita a seleção. Entretanto, a resolução parece permitir algum poder discricionário à escola, ao possibilitar transferências ao longo do ano, desde que seja assegurada a "adaptação [do aluno] às especificidades da escola do Programa Ensino Integral” (SÃO PAULO, 2013, p. 89).

A necessidade de trabalhar, seguida da não adaptação ao regime das escolas integrais, são os maiores fatores de seletividade ou evitação de estudantes e estabelecimentos. A inadaptação do aluno vai desde a inadequação ao tempo escolar ao não ajustamento às exigências, ritmos e disciplinas do período integral. Os alunos são conscientes da necessidade de observar a carga horária de mais de sete horas diárias e da sua presença e participação nas aulas, mas a escola também assume que um número expressivo de estudantes não consegue cumprir essas exigências. Alguns vão se integrando ao mundo do trabalho; outros não satisfazem as exigências acadêmicas, talvez porque não queiram, ainda segundo a escola, cumprir uma jornada de nove horas. No último caso, a escola faz esse movimento para que o estudante a deixe. Uma gerência pernambucana também destacou a existência de barreiras de acesso para os alunos em relação ao ensino integral, uma vez que essa modalidade exige a necessidade de ficar o dia todo na escola: "Tem escolas integrais nossas que começam com um número ' $x$ ' de matrículas e há pedidos de transferência durante $o$ ano, de meninos que conseguem um estágio remunerado, um emprego mais próximo de casa" (Pernambuco, alto cargo de órgão regional). De acordo com o diretor de uma das escolas:

Tem evasão daquele tipo de aluno que estava com a gente, que não queria trabalhar [academicamente]... a questão do ensino integral... Só estava aqui por causa dos pais. Conversamos com os pais e os mesmos decidiram retirá-los daqui e colocá-los numa escola regular. E eles estão bem, o problema é que eles não queriam ficar nove horas. [...] Para você ter uma ideia, nós tínhamos 35 alunos no $9^{\circ}$ ano e nos segundos anos $A$ e B, que era para ser hoje, houve essa evasão enorme de cerca de 10 a 12 alunos por turma (Pernambuco, diretor de escola

O Programa Ensino Integral (PEI), implantado em 2012, ampliou a jornada escolar permitindo o melhor atendimento aos alunos, desenvolvendo projetos de avaliação e recuperação da aprendizagem dos alunos. O desenho curricular dessas escolas é diferenciado, assim como os modelos pedagógicos e de gestão escolar, com instrumentos para planejamento, gerenciamento e avaliação das atividades pela comunidade. Para maiores informações ver Grosbaum e Falsarella (2016). 
Percebe-se, assim, certa "acomodação" da matrícula nas escolas de tempo integral. Mesmo em estados que não realizam uma seleção oficial, esta tende a ocorrer, na percepção dos agentes escolares, tanto do lado dos jovens, por considerarem que essas escolas não são apropriadas para eles - já que terão que trabalhar em algum momento do curso do EM ou porque não se julgam com o perfil adequado para estudar numa escola com altas expectativas de desempenho e dedicação; quanto do lado da escola, porque desestimulam os estudantes que são julgados com rendimento e disposições acadêmicos pouco adequados para um bom aproveitamento nessas instituições.

Nesse sentido, as políticas de ensino médio integral tendem a privilegiar determinado grupo de alunos, "geralmente os que já possuem bom desempenho - Escolas Técnicas (Etec) e EM Integral” (São Paulo, professor de escola de município de médio porte). Assim, embora a matrícula em tempo integral venha se ampliando nos quatro estados, a reação das escolas e dos estudantes e familiares também acaba contribuindo para tornar mais seletiva a cobertura, de acordo com o discurso dos agentes escolares. Se a própria oferta concomitante da matrícula em tempo integral e parcial já promove uma associação entre nível socioeconômico e matrícula num tipo e noutro de escola, essas reações acentuam essa associação.

Essas percepções são ratificadas, no caso de São Paulo, também pelo relatório do Tribunal de Contas do Estado de São Paulo (TCE, 2016). De acordo com o documento, os alunos do Programa Educação Integral (PEI) e do Projeto Escolas de Tempo Integral (ETI) ${ }^{10}$ da rede estadual de São Paulo ${ }^{11}$ reúnem características associadas a desempenhos acadêmicos mais elevados (motivação e comprometimento) em relação ao observado em escolas de tempo parcial, localizadas na mesma região. A participação da família na vida escolar desses estudantes também é mais ativa, se comparados aos responsáveis pelos alunos que frequentam as escolas convencionais da rede pública estadual. Além disso, o mapeamento do logradouro dos alunos matriculados nos PEl indicou que a matrícula não é composta por alunos que residem no mesmo bairro onde se situa a escola - e, menos ainda, em suas imediações. Verificou-se que a distância média entre a residência e o endereço das unidades é de 4,80 km. O relatório asseverou, ainda, que "a área média de abrangência dos PEI é de aproximadamente $72,34 \mathrm{~km}^{2}$ - superior ao de

10 Escolas de Tempo Integral (ETI), com ensino médio regular em um turno e oficinas no contraturno, mas esse tipo está sendo desativado.

11 Para mais informações sobre os dois programas ver o artigo "Ensino médio, educação profissional e desigualdades socioespaciais no estado de São Paulo”, de Grosbaum e Falsarella (2016), publicado neste número da Cadernos Cenpec. 
diversos bairros da capital paulista e, inclusive, de alguns municípios do Estado" (TCE, 2016, p. 6), confirmando, para São Paulo, os mesmos processos seletivos oficiosos que ocorrem nos demais estados.

As entrevistas realizadas revelam que, no limite, quando a escola não seleciona os alunos no ingresso, o faz durante o ano letivo: os alunos que não se enquadram no perfil dessas unidades têm seus processos transferidos.

Em São Paulo, de acordo com o Relatório do TCE (2016), parte significativa dos estudantes que iniciam o ano letivo em unidades do PEI deixa de frequentá-las nos meses seguintes. Nos dois primeiros anos, esse contingente correspondia a $20 \%$ do total de estudantes matriculados; nos dois anos seguintes, a transferência foi de 17\%. Parte das solicitações de transferência decorreu da inadaptação desses educandos às exigências e dinâmicas de funcionamento do programa.

Estes casos refletem as dificuldades desses alunos em corresponder às expectativas de aprendizagem estabelecidas pela comunidade escolar. Tanto que o desempenho acadêmico da maior parte dos transferidos esteve aquém do limite mínimo de aproveitamento em, pelo menos, uma das duas disciplinas consideradas para cálculo do Índice de Desenvolvimento da Educação do Estado de São Paulo (Idesp): Língua Portuguesa e Matemática (TCE, 2016, p. 4).

Outra seleção ocorre a partir do perfil dos alunos e de sua situação socioeconômica, fatores que acabam conduzindo a "escolha" do tipo de oferta do ensino médio. Isso quer dizer que, embora haja diversas possibilidades, as condições de vida dos estudantes impõem a orientação para um determinado modelo em detrimento de outro:

De acordo com o depoimento da gerência [...] outra dificuldade grande é que os estudantes precisam sair da sala de aula e ajudar a crescer a renda da família (Pernambuco, alto cargo da secretaria estadual de educação).

[Sobre o alto índice das taxas de transferidos, 112 alunos, a diretora justificou que] os alunos que não continuaram na escola são aqueles que precisam trabalhar, portanto, não têm perfil de alunos de escola de tempo integral (Goiás, diretor de escola da região metropolitana).

Assim, a diversificação da oferta pode, por um lado, atender a demandas específicas, mas também pode, por outro lado, acentuar desigualdades. Aqueles que financeiramente podem e querem se dedicar só aos estudos, preparando-se para o ingresso no ensino superior, estão no integral; já aqueles que precisam conciliar os estudos com o trabalho, seja por necessidades econômicas, individuais e/ou familiares, costumam frequentar o período parcial, especialmente no noturno ou na Educação de Jovens e Adultos (EJA).

Essa percepção é compartilhada por um coordenador regional do Ceará, 
quando afirma que "essa diversificação das escolas é importante porque atende vários públicos”, e pelo secretário de Educação do Ceará, quando reconhece que

\begin{abstract}
[...] eu acho que existe uma demanda e sempre existirá no noturno e que deverá ser atendida adequadamente no noturno e aí eu digo assim, adequadamente não é o que se faz hoje que é uma réplica malfeita do que se faz no diurno. Acho que essa diversidade tende a se tornar um problema de equidade e, acho que sendo bem pragmático, um problema de cada vez. O problema que a gente tentou resolver com a escola profissional de tempo integral é um problema de necessidade e aspirações da juventude e de suas famílias, necessidades econômicas, e, por outro lado, uma tentativa de afirmar que é possível construir um modelo de escola pública respeitada, que seja referência na sua comunidade, para contrapor um pouco esse discurso de que escola pública não funciona. Acho muito importante operar nesse nível simbólico, tanto para o estado, mas, sobretudo, para aquelas comunidades onde as escolas estão (Ceará, secretário estadual de Educação).
\end{abstract}

Ademais, no caso do Ceará, há que se destacar uma dimensão não perceptível e praticamente invisível do ensino médio regular, que se traduz na oferta de ensino médio público em escolas estaduais localizadas em municípios sede, às quais estão vinculadas matrículas de estudantes que assistem aulas em espaços localizados em distritos ou comunidades rurais, conhecidas como "extensões rurais" ou "anexos". Segundo dados obtidos junto à Seduc, em 2015 existiam 402 anexos vinculados a 173 escolas de ensino médio regular, e neles estavam matriculados 34.787 alunos, quantitativo que se aproxima dos números das escolas de ensino médio integrado à educação profissional. Dessa forma, o modo como o Estado vem atendendo a faixa etária de escolaridade correspondente ao ensino médio se configura em um problema de equidade no interior do sistema estadual. A comparação entre as condições de funcionamento do ensino médio integrado à educação profissional versus o ensino médio regular de turno único ofertado nos anexos expõe um problema que cedo ou tarde precisará ser enfrentado de modo a equacionar a questão da iniquidade.

Importa ressaltar, dessa reflexão, porém, o modo como as escolas de tempo parcial reagem a essas políticas. Mesmo pertencentes a uma mesma rede, as iniciativas governamentais podem ter efeitos diversos, como no caso de escolas de tempo parcial pernambucanas que, vendo-se em desvantagem em relação às unidades vizinhas de tempo integral, implementaram estratégias para lhes conferir reputação no entorno. Um caso observado foi o de uma escola que fez um convênio com uma instituição de estágio remunerado e, assim, adquiriu prestígio por inserir seus alunos no mercado de trabalho - trata-se de uma unidade que reconstruiu sua identidade no quadro das 
relações de interdependência competitiva entre escolas situadas num mesmo espaço de recrutamento de alunos (VAN ZANTEN, 2001). Era, antes, de uma escola reputada junto à vizinhança e com bons indicadores educacionais. Com a criação de uma escola de tempo integral nas proximidades, seus alunos com melhor desempenho foram recrutados por ela. A diretora passou a lidar com problemas de disciplina, professores desmotivados e baixo desempenho. Foi necessário construir, com a liderança da diretora, uma identidade que criasse um vínculo dos estudantes e professores com a escola.

Outro caso, com características semelhantes, também constatado em Pernambuco, mas em município com alto índice de ruralidade, foi o de uma escola - que também teve as características sociodemográficas de seu corpo discente alteradas pela criação de uma escola de tempo integral na vizinhança - transformar-se pela criação de uma nova identidade: a escola tornou-se, no município, uma referência na preparação para o Enem. Podem-se discutir as finalidades atribuídas à educação pelas escolas, mas o importante a reter aqui são as respostas que as escolas deram às políticas de criação de escolas de tempo integral e aos problemas por elas criados.

Outro elemento identificado nas políticas educacionais de três dos quatro estados (exceto Ceará, que não possui um currículo oficial) é a questão curricular, que se constitui como o segundo eixo de análise e será abordada no tópico seguinte.

\section{O CURRÍCULO DO ENSINO MÉDIO}

No que toca à dimensão do currículo e sua disseminação nas redes de escolas a partir de sistemas de acompanhamento e monitoramento que incorporam mecanismos informatizados e rotinas administrativas desenvolvidas por equipes técnicas que visitam grupos de escolas para interação in loco, as escolas também se posicionam.

Sobre a necessidade, conhecimento e implementação desses documentos curriculares, percebem-se visões distintas e algumas vezes antagônicas entre os gestores das secretarias e regionais e os diretores e professores de escolas, como podemos observar nos depoimentos a seguir.

O caso de Goiás é emblemático, uma vez que, na visão de técnicos da Secretaria de Educação, embora tenha deparado com situações conflituosas, o estado conseguiu estabelecer um "currículo referência” e, ao longo dos anos, as resistências estariam sendo vencidas, chegando aos dias atuais com 
“adoção quase universal”. A visão, porém, de alguns docentes entrevistados quanto à adequação do material contrapõe-se a essa percepção otimista, como podemos observar nos depoimentos a seguir:

\section{[...] Uma das deficiências que eu vejo no ensino médio é o currículo [...] As reformulações que eles fazem só mudam os nomes, mas continua a mesma coisa. Não conseguem enxugar, deixar o currículo mais claro, mais objetivo e realista. Eu acho que esta é uma dificuldade especialmente do professor do noturno (Goiás, professor de escola da região metropolitana).}

Quando se fala em políticas estaduais, podemos começar pelo currículo bimestral de Goiás, que nos é mandado, e que a gente tem que engolir. Isso não atende às expectativas, porque não tem a maioria dos currículos que são cobrados no Exame Nacional do Ensino Médio (Enem) e na Universidade de Brasília (UNB) [...] Quando a gente foge do currículo, chamam nossa atenção pela coordenação, porque não estamos seguindo à risca (Goiás, professor de escola de município de médio porte).

Os excertos apresentados revelam que os professores julgam o currículo inadequado, excessivo, pouco claro ou objetivo e que devem conciliá-lo com distintas exigências que interferem no planejamento curricular, como a política de avaliação e, em certa medida, de ingresso ao ensino superior (o Enem), bem como o exame de acesso à universidade. Essas percepções deixam claro que o currículo prescrito não é seguido "à risca”.

O distanciamento percebido - como também as exigências próprias do curso noturno - implica desacordos com as normativas de instâncias superiores, podendo gerar a refuta de tais orientações. Não é incomum, em processos de elaboração de políticas, o envolvimento de grupos na discussão e preparação do texto da política como estratégia de implementação, pois a participação confere reconhecimento e, de certo modo, identificação com a política, o que contribui para o afastamento das orientações como as citadas "que a gente tem que engolir [as decisões]" (Goiás, professor de escola da região metropolitana).

No caso pernambucano, parece haver um confronto entre as iniciativas de âmbito federal e estadual na política curricular. De acordo com a diretoria de uma escola, a gestão conjunta de professores e equipe gestora é responsável pela adaptação do currículo às avaliações externas e ao vestibular. Na visão do gestor, o excesso de disciplinas e de conteúdos chega a "sufocar" os estudantes, cabendo aos professores e à equipe gestora a reorganização e adequação do conteúdo dado. 
Então tem horas que eles ficam, de certa forma, sufocados, né?! Então a gente tem que pensar nesse jovem na parte técnica, que ele vai ser um profissional amanhã, mas também tem que prepará-lo para a continuidade, para o vestibular, para o Enem. A gente foca tanto na base comum quanto na base técnica. A gente segue a proposta curricular de Pernambuco,

que os Parâmetros Curriculares de Pernambuco (PCPE) de cada disciplina... A gente procura acompanhar, pois ele também está baseado nas diretrizes curriculares. Temos que estar trabalhando de acordo com a lei. Eu acho que a gente procura dar conta de tudo, de preparar esse menino para o Enem, para o vestibular da UPE, tanto quanto para base técnica (Pernambuco, diretor de escola da região metropolitana).

Para os estudantes, com uma estrutura de currículo mais direcionada, os alunos obteriam melhores resultados.

No ensino médio a gente já tem uma ideia do que a gente quer para o futuro, então eu acho que o desempenho melhoraria. Tipo, eu não curto Exatas e não pretendo seguir a área... Então

é meio que desnecessário. Ok., a gente poderia ver, mas por alto. Feito em outros países em que isso acontece, mas acaba sendo uma perda de tempo... Eu poderia estar focando os meus estudos numa área que eu vou usar futuramente [...] Eles botam muita coisa pra gente estudar sem que a gente vá exercer elas no futuro (Pernambuco, aluno de escola de município da região metropolitana).

Para um Professor Coordenador Pedagógico (PCP) de São Paulo, "a organização curricular é baseada no material do São Paulo Faz Escola, mas o livro didático também é um recurso, assim como a matriz do Saresp [Sistema de Avaliação de Rendimento Escolar do Estado de São Paulo], uma vez que o seu conteúdo está diluído no caderno do aluno e do professor" (São Paulo, professor coordenador pedagógico de escola da região metropolitana). Um diretor de uma das escolas investigadas afirmou que "o currículo único é muito bom, mas os 'enxertos' são fundamentais. Por isso, o livro didático tem que continuar: o livro didático é o enxerto no currículo. Os professores seguem o currículo oficial, mas inserem mais coisas" (São Paulo, diretor de escola da região metropolitana). De acordo com uma professora, "as políticas curriculares da Secretaria Estadual de Educação (SEE) entram em contradição com a realidade da escola por ter um currículo posto pelo estado que não contempla as necessidades do aluno e também não atende às exigências do Enem, por exemplo" (São Paulo, professora de escola de município de médio porte).

Em relação à adequação curricular, outro diretor considera que "A política da Secretaria de Educação de São Paulo para o ensino médio também está defasada e o currículo atende, em parte, às demandas e anseios dos jovens que frequentam a escola” (São Paulo, diretor de escola de município de médio porte). Para uma professora, “existem conteúdos ótimos, mas que dizem 
respeito à realidade das grandes cidades e não de um município do interior como este [...] tem alunos que nunca andaram de metrô ou trem, que nunca foram à praia. Como dar esses exemplos?” (São Paulo, professora de escola de município de pequeno porte e alto índice de ruralidade).

Por outro lado, vale ressaltar que as escolas percebem a associação entre o currículo e avaliações em larga escala, e que o caráter prescritivo que muitos desses documentos vêm assumindo tem relação intrínseca com as matrizes desses exames, como podemos observar nas afirmativas de diretores. A partir de 2010, as redes estaduais de ensino, em maior ou menor intensidade, passam a se envolver com o Exame Nacional do Ensino Médio (Enem) ${ }^{12}$, o que as leva a procurar incluir nos planejamentos escolares a matriz de referência deste exame e, com isso, alterar a proposta curricular então vigente, como podemos observar nos depoimentos.

\section{[...] em termos de Seduc, tem um material, uma proposta de currículo [o que contradiz a afirmação, pelos órgãos centrais, da inexistência de um currículo], já com base nos descritores do Enem e do Spaece [Sistema Permanente de Avaliação da Educação Básica do Ceará]. Aí a gente tem flexibilizado muito o currículo em função disso, a gente até já vê que o professor já está seguindo muito mais, deixando de seguir um livro, e está seguindo o currículo que seja construído mesmo (Ceará, diretor de escola da região metropolitana).}

As avaliações de larga escala afetam o currículo no sentido de incentivar a escola a ir além do currículo oficial posto pela Secretaria de Educação do Estado e buscar novas alternativas que contemplem o que é exigido nessas avaliações, tipo o Enem (São Paulo, diretor de escola de município de médio porte).

Olhe, quando você pega a proposta, cada disciplina, é tão grande, é tanta coisa que em todas elas, eu não me sinto segura de dizer o que e o quanto, mas em todas cabe um enxugamento. Existe, inclusive, e vocês sabem disso, um estudo, uma luta para isso, para ter um enxugamento, e a gente acha que isso vá acontecer logo. Tem que ir fazendo um paralelo: 'Está na proposta? Está no currículo? Está no Enem? Condiz com a cultura da nossa comunidade?’ (Pernambuco, diretor de escola de município de pequeno porte e alto índice de ruralidade).

Com certeza ficamos meio engessados, sempre com a intenção de querer sair bem na avaliação externa. Eu trabalho com Língua Portuguesa, por exemplo, e tem tanta coisa que poderíamos ver dentro da Língua Portuguesa que poderíamos ver de forma mais livre e espontânea, mas estamos tão preocupados em dar conta do currículo proposto por conta desses resultados nessas avaliações... (Pernambuco, diretor de escola de município de médio porte).

0 que se percebe nos depoimentos dos diretores é que com a proliferação dos sistemas estaduais de avaliação de larga escala e a nova configuração do Enem, via de regra, as escolas convivem com três documentos que apontam

12 Sobre a participação dos quatro estados no Enem 2014, ver o artigo "Contextos, políticas e resultados de avaliação no ensino médio: um estudo em quatro estados brasileiros" de Vieira; Vidal e Galvão (2016), publicado neste mesmo número da Cadernos Cenpec. 
em direção a um currículo: os documentos curriculares, a matriz de referência da avaliação estadual e a matriz de referência do Enem. Além disso, são constrangidos em sua ação por um ideário pedagógico - a ser posteriormente aprofundado - que os leva a buscar adaptar o currículo a uma suposta "realidade do aluno" e da "comunidade" em que se insere. Isso tem gerado dificuldades para a gestão da escola e um acentuado mal-estar docente, pois embora haja o reconhecimento de que as matrizes de qualquer exame são sempre versões reduzidas de propostas curriculares e um ideário pedagógico que o conduz a buscar trabalhar de modo próximo a uma suposta "realidade do aluno", a implantação de modelos variados de gestão por resultados leva as escolas a escolherem trabalhar com as matrizes dos exames como forma de preparar os alunos para eles, uma vez que a gestão escolar é avaliada pelo alcance de metas ou premiada pelos resultados obtidos.

No uso dos currículos estaduais, desse modo, os professores, apesar de um conjunto de mecanismos de controle - como se verá a seguir -, estão submetidos a um conjunto de constrições que precisam equacionar ao definir o que será ensinado, quer dizer, o currículo em ação: há, evidentemente, o currículo prescrito; mas há também o Programa Nacional do Livro Didático (PNLD), realizado em nível federal; também realizado pela União, há o Enem, nem sempre de acordo com os currículo estaduais; há as avaliações em larga escala, realizadas por estados e pela União; há as expectativas dos estudantes, que tendem a exigir negociações; há ainda as especificidades dos diferentes tipos de matrícula e clientela: os períodos parcial e integral; os turnos diurno e noturno e a modalidade EJA. Há, por fim, a própria intepretação que os docentes dão ao ideário pedagógico de "adequação à realidade dos alunos e das escolas": pode consistir na seleção de conhecimentos relevantes para a vida dos jovens, na utilização de abordagens metodológicas específicas, que partem dessa realidade e voltam a ela, depois de examinar conhecimentos científicos, acadêmicos e artísticos relevantes para a compreensão e modificação dessa realidade. Mas pode também esconder baixas expectativas em relação a esses estudantes.

Como já é possível perceber, outros aspectos que se relacionam fortemente com o currículo e que merecem destaque são a avaliação, o acompanhamento e o monitoramento. 
A iniciativa da Secretaria Estadual de Educação do Ceará em estimular os alunos das escolas públicas cearenses de ensino médio a fazer o Enem gerou uma adesão maciça a partir de 2010, provocando, por conseguinte, mudanças na gestão das escolas de modo a se ajustar às metas associadas a resultados nesses exames. A pesquisa constatou a presença de uma cultura de provas, de simulados e de diferentes tipos de atividades preparatórias visando à aplicação das avaliações externas em todas as escolas investigadas no estado, com maior ênfase nas de educação profissional em tempo integral, nas quais, ao que tudo indica, todos os diretores acompanham os resultados de seus alunos.

Em Pernambuco, por exemplo, as avaliações externas possuem grande força de influência na rotina escolar, seja na adaptação da avaliação interna ao modelo das externas e na exigência cada vez mais comum do fornecimento de dados quantitativos ao gestor estadual. Praticamente todos os profissionais entrevistados destacaram que suas rotinas são afetadas pelas avaliações e que, dia após dia, percebem que a escola se adequa a um modelo que prioriza primeiro o Enem e logo após as avaliações externas nacionais e estaduais. Essa forte preparação para a avaliação foi constatada em todos os estados, o que evidencia que, mesmo com o forte movimento de renovação curricular ocorrido no final da última década (CENPEC, 2015), as avaliações externas continuam a atuar como um forte indutor de uma cultura de avaliação nas escolas, bem como de seu currículo. Essa cultura e sua influência no currículo decorrem, ao que tudo indica e em larga medida, não apenas das avaliações externas, mas também das estratégias de acompanhamento e monitoramento, seja do uso do currículo, seja dos resultados do ensino-aprendizado.

No Ceará, a complexidade da organização e o nível de detalhamento da gestão por resultados no âmbito das escolas parecem variar em função do perfil dos gestores, "desde um minucioso acompanhamento turma a turma, aluno a aluno, como é o caso de uma escola de ensino médio integral do interior do Ceará, a uma abordagem centrada em aulas extras ministradas por professores voluntários, caso de uma escola regular da capital” (VIEIRA; VIDAL, 2016).

Os técnicos responsáveis por acompanhar e monitorar as escolas, por vezes, têm suas atribuições compreendidas, pelos agentes escolares, como as de fiscalização, especialmente nos sistemas em que predomina uma visão de gestão por resultados, gerando certa tensão quando presentes nas unidades. 
Quando a tutora está aqui, não pode [subir aula ou ficar no corredor e pátio], tem de ter cuidado com tudo, não pode nem ir ao banheiro. Eles dão cartas, dama para jogar e passar o tempo, não pode nem beber água e a gente tem de ficar quietinho (Goiás, aluno de escola de município da região metropolitana).

É muito difícil. Ninguém gosta de ter a cobrança, não. A gente gostaria que os resultados viessem por si só, mas toda atividade você precisa de um monitoramento, e você precisa saber onde você está e aonde você vai chegar (Ceará, diretor de escola de município da região metropolitana).

A Diretoria de Ensino envia periodicamente o Professor Coordenador do Núcleo Pedagógico (PCNP), que faz o acompanhamento do trabalho de sala de aula e verifica se o material enviado

pela Secretaria da Educação está sendo usado pelos professores e organiza a Orientação

Técnica (OT), para a qual todos os educadores são convocados de acordo com as disciplinas que ministram (São Paulo, professor coordenador pedagógico de escola de município de médio

porte).

A Secretaria de Planejamento e Gestão (Seplag) acompanha os resultados com relação ao Pacto pela Educação. São cinco critérios que eles nos questionam, quando está vermelho ou amarelo, mas quando está vermelho... Porque acendem os faróis... Vocês devem ter visto. Você pode me pegar aquele resultado que tem fixado na parede ali? Isso é para vocês verem o que eles mandam. Eles apresentam uma planilha que tem a foto de cada gestor. Ninguém mostrou a vocês, não? Acho que esse não é de 2014, o de 2014 está na sala dos professores, mas é isso. Nós não estamos mais no vermelho, olhem os critérios. Os critérios são esses aqui - a média externa, média interna (Pernambuco, professor de escola de município de médio porte).

\section{A bonificação por resultados, articulada à avaliação externa, embora adotada nos quatro estados pesquisados, é percebida de modo distinto por gestores e docentes. Para alguns, ela:}

[...] tirou a nossa titularidade, que foi tão trabalhada para ser conseguida e pela qual nós lutamos [...] o dinheiro que financeiramente entra como bônus, na realidade não é um bônus e sim o nosso dinheiro, que o Estado mudou de nome e paga de seis em seis meses no ano. (Goiás, diretor de escola de município da região metropolitana).

\section{Em Pernambuco, em geral, os depoimentos mostram apoio ao sistema de bônus devido à sua capacidade de motivação. Todavia, a maioria acredita que seria melhor investir em aumentos salariais, e em uma das escolas criticou-se seu efeito sobre o currículo, em virtude de avaliação, que resulta na bonificação, privilegiando as áreas de português e matemática:}

A nossa ideia é formar cidadãos para a sociedade e para a universidade. Teve escola que atingiu $100 \%$, mas vá na veracidade e pergunte na escola quantos passaram em uma federal. Foi 100\% de bonificação, 100\% em tudo, não questionaram nada do governo e ganharam $100 \%$. Pergunte quantos atingiram a federal. Nenhum. Nós [da escola X] zeramos, mas pergunte quantos atingiram. Vários atingiram federal. Nós aqui não trabalhamos em cima dessa bonificação (Pernambuco, professor de escola de município de pequeno porte e alto indice de ruralidade). 
Nas escolas pesquisadas no Ceará, a maioria dos diretores tem uma avaliação positiva acerca da política de bônus adotada pela Seduc, com apenas uma voz discordante na afirmação de que "em certo ponto ela ajuda a menosprezar algumas unidades" (Ceará, diretor de escola de município da região metropolitana). Entretanto, a concessão de prêmios para alunos com bom desempenho no Enem, valorizada pelos entrevistados, ao que tudo indica tem se constituído em fator de frustração, na medida em que a Secretaria de Educação tem encontrado dificuldades para fazer a distribuição de computadores para seus estudantes em tempo hábil.

\section{POLÍTICAS DE FORMAÇÃO DOCENTE}

A fragilidade e a descontinuidade de iniciativas de formação docente são manifestadas pelos educadores, assim como a inoperância de algumas formações que, em sua percepção, são concebidas a partir de modelos genéricos e que pouco atendem às demandas que enfrentam os docentes em sala de aula e a suas necessidades, decorrentes da realidade escolar:

\footnotetext{
O governo federal, no ano passado, tentou fazer curso de formação, mas na prática não funcionou, nada mesmo. Era uma coisa muito vaga, que a gente não sabe para que começa e nem aonde eles querem chegar; e o Estado nem se fala... O Estado não tem nenhum tipo de investimento nessa área, quando se ventila alguma coisa a gente vê que é só discurso, mas coisa prática que faz diferença na realidade da escola, nos cinco anos que eu trabalhei efetivo no Estado, não tem nada (Goiás, professor de escola de município da região metropolitana).
}

Em Pernambuco, São Paulo e Ceará, entre as políticas de formação docente, destaca-se o Pacto pelo Ensino Médio, uma iniciativa do governo federal, bem como ações dirigidas para docentes de disciplinas específicas como língua portuguesa e matemática, que são objeto das avaliações estaduais. Entre os professores, entretanto, não há clareza sobre o tipo de formação mais adequado. 
[...] a gente tem um horário, um período para formação. Tinha umas bolsas, as bolsas da Fundação Cearense de Apoio ao Desenvolvimento Científico e Tecnológico (Funcap)... Que o professor colocava um projeto e a partir desse projeto ele daria formação para os outros profissionais. Essa bolsa acabou, e desde que essa bolsa acabou, todas as formações que eu recebi foram da escola, e teve também outra formação que acabou que foi o Pacto, mas eu acredito que essa questão da formação... o governo deveria pensar a formação de forma mais concreta, porque na minha visão, formação concreta para professor é especialização,

é mestrado e doutorado. São formações pequenininhas, entendeu..., que na minha visão

ela surte um efeito mais pontual, mais localizado, muitas vezes a formação que vocêfez serviu para o mês. Deveria ter uma formação mais centralizada para os professores (Ceará, professor de escola de município da região metropolitana).

A gente entende que a formação são essas reuniões que a gente faz de planejamento, não deixa de ser uma formação, porque a gente pega a realidade da escola e vamos discutir em cima dela e traçar a meta (Ceará, diretor de escola de município da região metropolitana).

\section{Professores e diretores entrevistados também se referem a um tratamento diferenciado para os docentes efetivos e temporários, além de uma visão de formação dirigida para as fragilidades diagnosticadas nas avaliações de larga escala.}

Quem é da rede pública que é concursado tem direito a fazer muitas dessas atividades, esses cursos... O temporário é excluído dessa parte de fazer curso. Por exemplo: há alguns cursos em Sobral, só que só pode fazer quem é efetivo. Temporário não tem essa possibilidade de fazer esses cursos. É complicado porque a gente está ali no mesmo patamar como professores, mas no caso não há essa preocupação em formar professores que estão aqui também (Ceará, professor de escola de município da região metropolitana).

Toda a nossa formação é feita baseada nos resultados... Então, a gente faz uma análise com os professores dos resultados, os descritores que apresentam resultados baixos; então, a equipe aqui elabora material para trabalhar com os professores como suporte, eles trabalham na sala de aula e depois trazem um retorno para os técnicos e aí faz esse trabalho em conjunto, em parceria (Pernambuco, alto cargo da Secretaria Estadual de Educação).

Tem, mas pouco. Muito pouco e não são satisfatórias, não. Elas são muito básicas, só abrangem a prova externa do estado porque o estado tem que alcançar o índice nacional... Então elas abrangem mais a questão das provas externas (Pernambuco, professor de escola de município de médio porte).

A respeito da formação em São Paulo, o relatório do TCE (São Paulo, 2016) revelou que nas escolas de tempo integral, em 2015, o número de eventos de formação e aperfeiçoamento profissional dirigido às escolas do Programa Ensino Integral (PEI) foi superior aos reservados a docentes e gestores que atuam nas escolas do Projeto Escola de Tempo Integral (ETI). Entretanto, o 
relatório não apresenta os dados das escolas regulares, pois não figuravam como objetos de investigação.

O que se depreende das percepções dos atores que atuam nas escolas é que as políticas públicas concebidas no âmbito dos governos (federal ou estadual) se capilarizam de forma diversa, e sua aceitação e implementação dependem, em parte, de que os processos desenvolvidos para sua execução sejam mais ou menos democráticos e participativos e em que medida a escola tem autonomia para colocá-los em movimento. 0 que se captou por meio dos depoimentos dos atores escolares é que sobrevivem resistências, na maioria das vezes veladas, mas que estão ali. Observa-se também uma adesão aos modelos propostos, embora muitos profissionais não deixem de se posicionar de forma crítica em relação às diversas políticas implementadas. Observase, por fim, que parte das reações e respostas negativas decorre também de problemas na própria formação dos docentes e gestores: a "realidade local ou do aluno", muitas vezes, em vez de ser o ponto de partida para a abordagem dos conteúdos curriculares, torna-se o ponto de chegada, limitando o currículo; assim como para as políticas dos estados, também para gestores e professores não é clara a função do EM, ora voltado para a preparação para o Enem e para o ingresso no ensino superior, ora encarado como uma etapa terminal da educação básica. Tampouco, como já se apontou, é claro o sentido de pertença a uma rede ou sistema de ensino. Certamente, esses problemas estão relacionados às próprias políticas de formação de docentes - cujas insuficiências eles mesmos apontam - e que parecem ser o calcanhar de Aquiles do modelo que vem baseando as políticas para o EM dos quatro estados, descritas em Batista et al. (2016).

\section{CONSIDERAÇÕES FINAIS}

Como ficou demonstrado, as políticas não deixam de ser também concebidas nas escalas locais, esfera onde é decisivo o modo como as escolas as percebem ou “encenam" tais políticas dos órgãos centrais - não apenas implementandoas, mas também as recriando, ou, para usar os termos de Ball, Maguire e Braun (2012), recontextualizando-as. Se é verdade, por um lado, que estas dependem de muitos fatores que ultrapassam a esfera decisória da própria escola, é também, por outro lado, que nesse espaço de relativa autonomia e intervenção boa parte de seus êxitos ou fracassos é definida.

Embora integrem uma mesma rede, as escolas têm uma história e um protagonismo e, por isso mesmo, recontextualizam as políticas articulando 
elementos de uma cultura organizacional própria. Segundo Torres (2005, p. 416), esta é construída na confluência entre diferentes forças que compõem um eixo horizontal, integrado por "fatores exógenos" e "fatores endógenos", os quais, por sua vez, se articulam a um eixo vertical, o qual expressa a relação entre "estrutura" (formal) e "ação" (informal). Da intersecção entre essas forças resultam “quadrantes”, com distintas possibilidades combinatórias.

Com a emergência de modelos de ensino médio de tempo integral e ensino médio integrado à educação profissional (caso cearense), a diversificação das condições da oferta de ensino médio, presente antes também nos turnos diurnos, noturno e nas escolas ou extensões rurais, se intensifica e revela condições desiguais de atendimento dessa população. Antes percebida como demanda decorrente de condições socioeconômicas ou até mesmo territoriais adversas, agora se expressa como uma preocupação para o Estado.

Um regime de sete horas ou mais diárias impõe critérios que levam à exclusão de parcela expressiva de jovens, aumentando a iniquidade entre escolas, alunos e até mesmo condições laborais dos professores e gestores. Como reação, é possível identificar mecanismos ou estratégias, sejam eles diretos ou indiretos, de seleção dos alunos. A pesquisa identificou três tipos de filtro: i) critérios de seleção para ingresso, mediante histórico do rendimento acadêmico dos alunos; ii) seleção ao longo do processo, quando o estudante é orientado a se transferir por não se enquadrar no perfil da escola, seja pela jornada de tempo ampliada (acima de sete horas diárias), seja pelo desacordo às exigências ou ritmos do período integral; iii) seleção, antes mesmo de ingressar nesse modelo, diante da necessidade de trabalhar para complementação do orçamento doméstico.

Ademais, as transformações no perfil demográfico dos alunos, das famílias, dos docentes, aliadas às condições de infraestrutura das escolas de atendimento integral, acentuam as desigualdades das oportunidades educacionais. Embora se pretenda ampliar a abrangência e cobertura da demanda, a política diferenciada das escolas, de certo modo, também acaba por se tornar mais seletiva, acentuando as desigualdades. A "escolha" do tipo de ensino médio acaba sendo orientada pelo perfil do aluno, sua situação socioeconômica, seu rendimento escolar ou mesmo seu comportamento.

No relatório do Tribunal de Contas do Estado (TCE-SP, 2016, p. 7-8), por exemplo, a equipe de fiscalização formulou as seguintes propostas de encaminhamento, dirigidas à Secretaria de Estado da Educação, sobre os modelos de educação em período integral existentes na rede pública estadual 
de ensino - Programa Educação Integral (PEI) e Projeto Escolas de Tempo Integral (ETI) de 2012 a 2015:

(1) Estabelecer as próximas unidades do Programa Educação Integral em bairros e distritos caracterizados pela elevada vulnerabilidade socioeconômica de seus moradores;

(2) estudar a elaboração de outras estratégias, auxiliares das tecnologias pedagógicas já introduzidas pelo programa, que garantam a permanência de todos os estudantes matriculados em suas unidades, sobretudo dos que apresentam dificuldades em corresponder às exigências acadêmicas estabelecidas pelo modelo;

(3) estudar a viabilidade de políticas de concessão de bolsas que impeçam a transferência dos alunos que, premidos pela necessidade de contribuir com sua renda familiar, passam a dedicar-se a atividades de natureza profissional, inviabilizando sua permanência nos estabelecimentos do programa;

(4) estabelecer como critério principal para a atribuição das matrículas nas unidades do PEI, quando o número de interessados for superior ao de vagas disponiveis, a distância mínima entre a residência daqueles e a localização da escola [...].

A respeito da questão curricular, observa-se a coexistência de diferentes orientações, ao lado dos documentos curriculares estaduais: o livro didático distribuído pelo PNLD, a matriz de referência da avaliação estadual e a matriz do Enem, os exames estaduais, as concepções dos docentes sobre a necessidade de adequação do currículo prescrito à realidade dos alunos e de seu contexto. Como se viu, as avaliações, associadas aos mecanismos de monitoramento dos resultados das escolas, parecem possuir um forte impacto na definição do currículo escolar. Essa configuração mostra um desconforto, tanto por parte da gestão como dos docentes.

Considerando as diferentes culturas organizacionais que existem nas variadas escolas, as políticas orientadas para a promoção da equidade e superação da desigualdade merecem ser objeto de atenção particular. Isso porque, se os efeitos produzidos pelas políticas nas escolas não são necessariamente esperados, é nesse espaço de relativa autonomia e intervenção que se define boa parte do êxito ou fracasso das políticas.

De maneira geral, chamou a atenção das equipes de pesquisa locais o visível engajamento das equipes gestoras das escolas integrantes da amostra no trabalho cotidiano de ensino-aprendizagem. Em se tratando de unidades localizadas em contextos socioespaciais vulneráveis, foi possível perceber que as unidades selecionadas parecem se constituir como espaços preservados em meio a um entorno frequentemente marcado pela violência e por condições adversas. A ausência de espaços de convivência e de lazer no território onde 
estas estão situadas acaba por contribuir para que se configure um pacto virtuoso entre comunidade e escola para assegurar as condições mínimas necessárias para a realização do trabalho pretendido.

As escolas visitadas, com efeito, especialmente as de tempo parcial, não possuem estruturas físicas excepcionais; ao contrário, promovem uma reinvenção e significação de espaços físicos relativamente precários, proporcionando uma cultura de reconhecimento e acolhimento da(s) juventude(s) que nelas se fazem presentes. Professores e alunos em convivência relativamente harmoniosa e amistosa evidenciam que, a despeito de todas as dificuldades, há uma sinergia promissora nessas comunidades de aprendizagem. Na verdade, como a maioria das escolas brasileiras, também estas realizam seu trabalho em um cenário permeado por dificuldades estruturais e conjunturais.

De modo geral, as políticas educacionais, sejam elas formuladas pelo governo federal ou estadual, chegam às escolas como "tarefa a ser cumprida". As escolas não costumam ser indagadas sobre as iniciativas que a elas chegam sem consulta prévia. Entretanto, com senso pragmático, delas tendem a fazer bom uso. Tome-se, por exemplo, as políticas de avaliação de resultados, concebidas pelo governo federal e pelos governos estaduais. As escolas visitadas as incorporam às suas rotinas, desenvolvendo estratégias próprias para lidar com elas, o que está articulado às suas próprias peculiaridades. 


\section{Reactions of state educational policies in schools: a case study in schools in Ceará, Goiás, Pernambuco and São Paulo}

Abstract: This article aims to analyze how secondary education schools in four Brazilian states - Ceará, Goiás, Pernambuco and São Paulo - react to the policies designed by state central agencies. The reactions - collected from the accounts of principals, pedagogic coordinators, teachers and students - are presented according to five dimensions of the common model that organizes policies in the four states: offer diversification; curriculum; assessment of academic performance results; monitoring of the teaching-learning process; and teacher training/recruiting. The analysis showed that the effects of policies on schools are not always the expected ones. Diversification in the conditions of secondary education offer aggravated service inequalities, evidencing the need for policies focused on promoting equality.

Keywords: Secondary education. Educational policy. Implementation. Reactions of schools. 


\section{Reacciones de las políticas educativas estatales en las escuelas: un estudio de caso en escuelas de Ceará, Goiás, Pernambuco y São Paulo}

Resumen: Este artículo pretende analizar cómo las escuelas de enseñanza media de cuatro estados brasileños Ceará, Goiás, Pernambuco y São Paulo reaccionan a las políticas concebidas por los órganos centrales estatales. Las reacciones captadas a partir de testimonios de directores, coordinadores pedagógicos, profesores y estudiantes se presentan en función de cinco dimensiones del modelo común que organiza las políticas de los cuatro estados: diversificación de la oferta; plan de estudios; evaluación de los resultados del rendimiento escolar; monitoreo del proceso enseñanzaaprendizaje y formación/reclutamiento de profesores. El análisis mostró que los efectos producidos por las políticas en las escuelas no son siempre los esperados. La diversificación de las condiciones de la oferta de enseñanza media intensificó condiciones desiguales de atención, lo que evidencia la necesidad de políticas para promover la equidad.

Palabras clave: Enseñanza media. Política educacional. Implementación. Reacciones de las escuelas. 


\section{REFERÊNCIAS}

ALVES, L. et al. Seleção velada em escolas públicas: práticas, processos e princípios geradores. Educação e Pesquisa, São Paulo, v. 41, n. 1, p. 137-152, jan./mar. 2015.

BALL, S. J.; MAGUIRE, M.; BRAUN, A. How schools do policy: policy enactments in secondary schools. Londres: Routledge, 2012.

BARROSO, J. O Estado, a educação e a regulação das políticas públicas. Educação \& Sociedade, Campinas, v. 26, n. 92, p. 725-751, Especial - Out. 2005.

BATISTA, A. A. G. et. al. Políticas para o ensino médio e desigualdades escolares e sociais: os casos do Ceará e de Goiás, Pernambuco e São Paulo. Cadernos Cenpec, São Paulo, v. 6, n. 2, 2016.

; CARVALHO-SILVA, H. H. Família, escola, território vulnerável. São Paulo: Cenpec, 2013.

CENPEC. Currículos para os Anos Finais do Ensino Fundamental: concepções, modos de implantação e usos. Relatório Final, São Paulo, 2015. Disponível em: 〈http://ftp.cenpec.org.br/com/portalcenpec/biblioteca/Relatorio_Pesquisa_ Curriculos_EF2_Final.pdf〉. Acesso em 4 de abril de 2016.

DALE, R. A sociologia da educação e o Estado após a globalização. Educação \& Sociedade, Campinas, v. 31, n. 113, p. 1099-1120, out./dez. 2010.

ÉRNICA, M.; BATISTA, A. A. G. A escola, a metrópole e a vizinhança vulnerável. Cadernos de Pesquisa, v. 42, n. 146, p. 640-666, ago. 2012.

FULLAN, M. O significado da mudança educacional. Tradução Ronaldo Cataldo Costa. 4. ed. Porto Alegre: Artmed, 2009. 303 p.

GROSBAUM, M. W.; FALSARELLA, A. M. Ensino médio, educação profissional e desigualdades socioespaciais no estado de São Paulo. Cadernos Cenpec, São Paulo, v. 6, n. 2, 2016.

MAROY, C. Em direção a uma regulação pós-burocrática dos sistemas de ensino na Europa? In: OLIVEIRA, D. A.; DUARTE, A. (Org.). Políticas públicas e educação: regulação e conhecimento. Belo Horizonte: Fino Traço, 2011. p. 19-46. 
PASSONE, E. F. K. Fracasso na implementação de políticas educacionais: uma abordagem pelo discurso psicanalítico. 174p. Tese (Doutorado)-Faculdade de Educação, Universidade Estadual de Campinas, Campinas, 2012.

RIBEIRO, V. M.; MELLO, H. D.; BATISTA, A. A. G. La vulnérabilité sociale du territoire dans les grands centres urbains brésiliens et l'inégalité scolaire. Diversité (Montrouge), 3ํTrim., p. 93-100, 2015.

SÃO PAULO. Resolução SE no 49, de 19 de julho de 2013. Diário Oficial Poder Executivo - Seção I, São Paulo, 123(135)-89, 23 de julho de 2013.

TORRES, L. L. Cultura organizacional no contexto escolar: o regresso à escala como desafio na reconstrução de um modelo teórico. Ensaio: Avaliação e Políticas Públicas em Educação, Rio de Janeiro, v. 13, n. 49, p. 435-451, out./ dez, 2005.

TRIBUNAL DE CONTAS DO ESTADO DE SÃO PAULO (TCE-SP). Relatório de fiscalização de natureza operacional sobre os modelos de educação em período integral existentes na Rede Pública Estadual de Ensino. São Paulo, SP, 2016.

VAN ZANTEN, A. L'école de la périphérie: scolarité et ségrégation en banlieue. Paris: PUF, 2001.

VIEIRA, S. L.; VIDAL, E. M. Ensino médio no Ceará: igualdade versus qualidade na implementação do direito à educação. Cadernos Cenpec, São Paulo, v. 6, n. 2, 2016.

; _______; GALVÃO, W. N. M. Contextos, políticas e resultados de avaliação no ensino médio: um estudo em quatro estados brasileiros. Cadernos Cenpec, São Paulo, v. 6, n. 2, 2016.

Sobre os autores:

Sofia Lerche Vieira é doutora em Filosofia e História pela Pontifícia Universidade de São Paulo (PUC/SP). Atua como professora do Programa de Pós-graduação em Educação da Universidade Estadual do Ceará (Uece).

E-mail: sofialerche@gmail.com

Eloísa Maia Vidal é doutora em Educação pela Universidade Federal do Ceará e professora da Uece.

E-mail: eloisamvidal@yahoo.com.br 
Pâmela Felix Freitas é doutoranda em Educação pela USP, mestre em Educação pela mesma instituição e pesquisadora do Cenpec.

E-mail: pamela.freitas@cenpec.org.br

Antônio Augusto Gomes Batista é doutor em Educação pela Universidade Federal de Minas Gerais e coordenador de Desenvolvimento de Pesquisas do Cenpec.

E-mail: antonio.batista@cenpec.org.br

Recebido em: outubro de 2016

Aprovado em: novembro de 2016 